\title{
Levantamento de plantas medicinais cultivadas no município de Solânea, agreste paraibano: reconhecimento e valorização do saber tradicional
}

SILVA, M.D.P.'; MARINI, F.S.2*; MELO, R.S. ${ }^{2}$

${ }^{1}$ Centro de Ciências Humanas Sociais e Agrárias, Universidade Federal da Paraíba, Campus III, CEP.: 58.220000, Bananeiras-PB. ${ }^{2}$ Programa de Pós Graduação em Ciências Agrárias (Agroecologia) - Departamento de Agricultura, Centro de Ciências Humanas Sociais e Agrárias, Universidade Federal da Paraíba. *Autor para correspondência: fsmarini@yahoo.com.br

\begin{abstract}
RESUMO: Objetivou-se neste trabalho reconhecer e sistematizar o conhecimento tradicional sobre as espécies medicinais, as indicações terapêuticas, as formas de uso e as técnicas de produção e comercialização de plantas medicinais no agreste nordestino, no município de Solânea, Paraíba. Visitas, entrevistas e amostragem foram realizadas a agricultores familiares da região por meio de entrevistas semiestruturadas utilizando a técnica de turnê guiada. Após as visitas foi identificada uma atriz - informante. Foi feito um herbário com as plantas medicinais encontradas, nas quais foram identificadas e categorizadas quanto às indicações terapêuticas de acordo com a Classificação Estatística Internacional de Doenças e Problemas Relacionados à Saúde. Foram verificadas 59 espécies com propriedades medicinais distribuídas em 36 famílias botânicas, com o predomínio da família Lamiaceae. Enfermidades de afecções digestivas foram as mais indicadas. O chá foi o preparado de maior frequência.
\end{abstract}

Palavras Chave: Caatinga, etnoconhecimento, etnobotânica

\begin{abstract}
A survey of cultivated medicinal plants from Solanea, dry area of Paraiba: recognition and recovery of the traditional knowledge. The aim of this work was to recognize and to order the traditional knowledge about the medicinal species, the therapeutic indications, the application forms, and the productions and marketing techniques of medicinal plants in the dry area of the northeast, in the city of Solanea, Paraíba. Visits, interviews and sampling were conducted to family farmers in the region through semi-structured interviews using the guided tour technique. A herbarium was built with the medicinal plants found and they were identified and classified regarding their therapeutic indications according to the Diseases International Statistical Classification and the Health Related Problems. 59 species with medicinal properties were identified and distributed in 36 different botanical families, with the Lamiaceae family predominance. The tea preparation was the more frequent one.
\end{abstract}

Keywords: Caatinga, ethnoknowledge, ethnobotany

\section{INTRODUÇÃO}

Cerca de $80 \%$ da população mundial depende de medicamentos derivados de plantas para o cuidado da saúde (Gurib-Fakim, 2006). O uso dessas plantas é comum entre as famílias rurais nordestinas, cuja maioria está constituída de plantas silvestres, utilizadas no atendimento primário de suas necessidades básicas de saúde (Matos \& Bezerra, 1993).

O uso de plantas com o objetivo de tratamento de enfermidades pode estar associado à comprovação de sua eficácia, com o uso popular.
O referencial de conhecimento aqui utilizado é tradicionalmente construído com outros saberes, embora distintamente particularizado como medicina popular. Suas propriedades são constantemente validadas por experiências e saberes passados de geração para geração e, na maioria das vezes, transmitidas oralmente (Machado, 2009).

O conhecimento tradicional pode ser entendido como "o conjunto de saberes e saberfazer a respeito do mundo natural e sobrenatural, transmitido oralmente, de geração em geração" e 
somente pode ser corretamente interpretado dentro do contexto cultural e ambiental em que o ator está inserido (Diegues et al., 2000).

Por outro lado, observa-se que com o crescente avanço da indústria farmacêutica, o consumo de remédios caseiros à base de plantas foi sendo substituído por remédios industrializados, levando as pessoas a optarem pela facilidade dos remédios na farmácia, trazendo a inibição do uso caseiro de plantas medicinais e o esquecimento dos saberes populares (Bruning et al., 2012).

Para Pilla et al. (2006), a atribuição do nome de remédios industrializados ou de substâncias ativas a muitas plantas, tais como: vick (Acanthaceae), antibiótico (Alternanthera brasiliana), novalgina (Achillea milllefolium) e insulina (Cissus cf. tinctoria), demonstra a influência da medicina alopática no meio popular. Os autores sugerem que a perda da biodiversidade original contribui para o afastamento das pessoas do contato com a flora e desta forma as plantas usadas com fins terapêuticos passam a ser cada vez mais restritas a ambientes antropizados.

Esse contato intensificado com os centros urbanos pode acarretar em alterações na rede de transmissão do conhecimento tradicional sobre plantas medicinais. Por isso, ao estudar o complexo da medicina popular, deve-se enfatizar a necessidade de estudar simultaneamente a pessoa detentora deste conhecimento e o ambiente onde essas práticas são espontaneamente aceitas, ultrapassando-se os limites da botânica aplicada (Albertasse et al., 2010).

Em junho de 2006 o governo federal aprovou a Política Nacional de Plantas Medicinais e Fitoterápicos, por meio do Decreto $\mathrm{n}^{\circ} 5.813$, a qual se constitui em parte essencial das políticas públicas de saúde, meio ambiente, desenvolvimento econômico e social como elementos fundamentais de transversalidade na implementação de ações capazes de promover melhorias na qualidade de vida da população brasileira (Brasil, 2006).

Este decreto promove ainda o reconhecimento das práticas populares de uso de plantas medicinais e remédios caseiros. Diante disso, as plantas medicinais desempenharão um papel cada vez mais importante na saúde, cultura e renda da população e na conservação e preservação das espécies vegetais. Neste sentido é indiscutível resgatar e valorizar essas práticas.

Apesar de serem produtos naturais, o aproveitamento adequado dos princípios ativos de uma planta exige o preparo correto e o uso adequado para trazer benefícios à saúde (Arnous et al., 2005).

Dentro deste contexto, o presente trabalho teve como objetivo reconhecer e sistematizar o conhecimento tradicional sobre as espécies medicinais, as indicações terapêuticas, as formas de uso e as técnicas de produção e comercialização de plantas medicinais no agreste nordestino, no município de Solânea, Paraíba.

\section{MATERIAL E MÉTODOS}

O trabalho foi desenvolvido no município de Solânea que está localizado na Microrregião do Curimatau Ocidental (Latitude $06^{\circ} 46^{\prime} 40^{\prime \prime} \mathrm{S}$ e Longitude $35^{\circ} 41^{\prime} 49^{\prime \prime} \mathrm{W}$ ) do Agreste paraibano, na região Nordeste do Brasil. O clima é do tipo As' (Tropical Chuvoso), quente e úmido, segundo classificação climática de Köppen-Geiger. A estação chuvosa se inicia em janeiro/fevereiro com término em setembro, podendo se adiantar até outubro. A temperatura média é de $25^{\circ} \mathrm{C}$. O município de Solânea tem uma particularidade, está situada numa Mesorregião do Agreste da Paraíba, no qual estão situadas entre duas unidades morfoclimáticas, - Brejo e o Curimatau, sendo uma úmida e outra semiárida, respectivamente, o que lhe garante uma fisionomia de área de transição (Ferreira, 2010).

Este trabalho foi realizado por uma ação de extensão e pesquisa vinculada ao Núcleo de Ensino Pesquisa e Extensão em Agroecologia (NEPE) do Centro de Ciências Humanas Sociais e Agrárias (CCHSA) da Universidade Federal da Paraíba (UFPB) em parceria com a Organização não Governamental de Integração da Família (ONGIFA).

Na década de 1990, a Catequese Familiar do município de Solânea, grupo que deu origem à ONGIFA, juntamente com outras entidades (ONG e movimentos sociais) propuseram um diagnóstico na comunidade de Bom Sucesso do município de Solânea-PB, focalizando a temática da saúde familiar. A ação buscou resgatar as experiências das pessoas mais velhas na comunidade em relação aos tipos de enfermidades que mais ocorriam no local. Após o diagnóstico, uma alternativa encontrada foi realizar intercâmbios, encontros de formação, convivência com a natureza e uso de plantas medicinais e os resultados da iniciativa geraram informações que valorizaram os saberes dos agricultores(as) e, com isso, foram resgatadas e identificadas experiências destes com as plantas medicinais mais utilizadas na região do agreste paraibano. Isso resultou em um grupo de agricultores(as) familiares organizados que passaram a preservar o conhecimento do uso e as indicações dessas plantas na região.

Neste trabalho foram realizadas entrevistas semiestruturadas aos agricultores(as) familiares durante os anos de 2012 e 2013, em visitas às propriedades e em dias de campo. O roteiro abordava perguntas sobre a experiência do conhecimento tradicional sobre as espécies medicinais, as indicações terapêuticas, as formas

Rev. Bras. PI. Med., Campinas, v.17, n.4, supl. II, p.881-890, 2015. 
de uso e as técnicas de produção e comercialização das plantas medicinais. Foi utilizada a técnica da turnê guiada conforme descrita por Albuquerque et al. (2010). Para tanto foram realizadas caminhadas nas residências e quintais. Depois das visitas foi identificada uma atriz - informante - selecionada devido à riqueza de seus conhecimentos e a grande diversidade de plantas presentes em sua propiedade, principalmente, devido a sua importância como guardiã dos saberes para a preservação das plantas medicinais no agreste paraibano.

As plantas encontradas foram fotografadas e, partes dessas, herborizadas como exsicatas. As exsicatas foram preparadas no Laboratório de Tecnologia de Sementes do CCHSA/UFPB para análise e identificação das espécies, com auxílio de um grupo de pesquisadores das Ciências Agrárias, Agronomia e Biologia.

A identificação taxonômica foi realizada com base em pesquisas bibliográficas de Lorenzi \& Souza (2000) e de Lorenzi \& Matos (2008), utilizando se a base de dados do Missouri Botanical Garden (MOBOT, 2012).

As plantas medicinais encontradas foram categorizadas quanto às indicações terapêuticas de acordo com a Classificação Estatística Internacional de Doenças e Problemas Relacionados à Saúde proposta pela Organização Mundial da Saúde (W.H.O., 2010).

\section{RESULTADOS E DISCUSSÃO}

O levantamento evidenciou 59 espécies distribuídas em 36 famílias botânicas (Tabela 1). Estas foram identificadas pelo etnonome e nome científico, as famílias botânicas, as indicações terapêuticas ditas pela entrevistada, a parte da planta utilizada e o modo de preparo baseadas nos conhecimentos tradicionais e adquiridos pelos agricultores ao longo das suas experiências.

Verificou-se que o maior número de espécies encontradas pertence a família Lamiaceae $(18,64 \%)$, seguida por Asteraceae e Bignoniaceae (5,08\%), Annonaceae, Costaceae, Crassulaceae, Euphorbiaceae, Lauracea, Myrtaceae, Poacea, Rutaceae, e Solanaceae $(3,39 \%)$ e as demais com $1,69 \%$.

Registros de identificação de plantas medicinais no Nordeste verificaram que famílias com maiores representatividade foram Fabaceae, Euphorbiceae, Cactaceae e Lamiaceae no estado do Rio Grande do Norte (Roque et al., 2010); Leguminosae, Euphorbiaceae, Lamiaceae e Solanaceae no estado do Piauí (Oliveira et al., 2010) e Leguminosae e Euphorbiaceae na Paraíba (Marinho et al., 2011). Entretanto, neste trabalho observou-se a maior representatividade de Lamiaceae, Asteraceae e Bignoniaceae, evidenciando a representatividade de plantas exóticas e nativas na medicina tradicional da região.

As espécies de plantas medicinais observadas nesse trabalho foram cultivadas por agricultores familiares em seus quintais, adquiridas com o passar dos anos, entre os familiares, vizinhos e durante a troca de conhecimentos em intercâmbios entre famílias de diferentes cidades, formando um rico acervo vegetal. O que corrobora com os dados de Marinho et al. (2011), no qual se constatou que as trocas de informações de uso dessas plantas, além das próprias matrizes, entre parentes, amigos e vizinhos se faz constantemente e permite a transmissão do etnoconhecimento repassado aos descendentes.

Percebe-se a importância da identificação botânica como primeiro passo em trabalhos de etnoconhecimento, porque espécies diferentes com características morfológicas semelhantes são conhecidas pelo mesmo nome popular e uma mesma espécie recebe mais de uma denominação, seja pela sua ação ou características morfológicas (Penso, 1980). Isto assegura o correto uso aos novos usuários, pois é sabido que existe grande variação nos seus constituintes químicos.

O uso de plantas medicinais para o tratamento de doenças ou para a manutenção da saúde é a primeira opção dentre as famílias entrevistadas. A busca diretamente na "Farmácia Viva", o que precisam para produzir os remédios caseiros, minimiza as dificuldades de deslocamento até o município onde são oferecidos serviços da medicina tradicional.

A "Farmácia Viva" foi uma termologia criada pelos agricultores(as) familiares, para validar as plantas medicinais e seu amplo uso popular regional. Dessa forma, essa iniciativa atenderia as pequenas comunidades para produzir e disponibilizar estas à população, o que inspirou diversas ações em todo Brasil, tanto em instituições governamentais como movimentos sociais. Entretanto, a insuficiência de suporte político, bem como as características peculiares inerentes as plantas medicinais e a qualificação das iniciativas municipais, geram a necessidade de serem realizadas normativas legais para assegurar a qualidade, a segurança e a eficácia dos recursos da saúde (Michiles, 2004).

Entre as plantas citadas, a arruda $(R$. graveolens), a babosa (A. vera), o confrei ( $S$. officinale) são usadas para debelar diferentes patologias. Em trabalho realizado no município de Ipê-RS, Ritter et al. (2002) destacaram essas espécies devido a sua toxidade estabelecida e cujo uso interno deve ser desaconselhado.

Foi observado que a arruda foi indicada para o tratamento de cólicas menstruais, dores de dente

Rev. Bras. PI. Med., Campinas, v.17, n.4, supl. II, p.881-890, 2015. 
TABELA 1. Lista das famílias, nome científico e etnonome, indicação terapêutica, formas de uso e parte utilizada para o combate a enfermidade entre os agricultores(as) familiares no agreste paraibano nos anos de 2012-2013.

\begin{tabular}{|c|c|c|c|c|}
\hline Família/ Nome Científico & Etnonome & Indicação terapêutica & Formas de Uso & Parte Utilizada \\
\hline \multicolumn{5}{|l|}{ Acanthaceae } \\
\hline Justicia pectoralis Jacq. & Chambá & tosse / gripe & chá / lambedor ${ }^{1}$ & folhas \\
\hline $\begin{array}{l}\text { Amaranthaceae Alternanthera } \\
\text { brasiliana (L.) O. Kunt }\end{array}$ & Penicilina & infecção urinária & 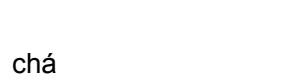 & \\
\hline \multicolumn{5}{|l|}{ Anacardiacae } \\
\hline Anacardium occidentale L. & Cajueiro Roxo & $\begin{array}{l}\text { gastrite / diabetes / inflamação: } \\
\text { ovário, bexiga ou útero }\end{array}$ & 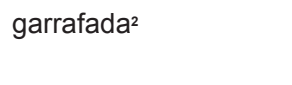 & casca \\
\hline \multicolumn{5}{|l|}{ Annonaceae } \\
\hline Annona crassiflora Mart. & Araticum & Rins & chá & folhas \\
\hline Anona muricata $\mathrm{L}$. & Graviola & $\begin{array}{l}\text { colesterol / inibidor de câncer / } \\
\text { inflamação }\end{array}$ & $\begin{array}{l}\text { chá / garrafada / } \\
\text { tintura }\end{array}$ & folhas \\
\hline \multicolumn{5}{|l|}{ Apiaceae } \\
\hline Foeniculum vulgare Mill. & Erva Doce & $\begin{array}{l}\text { calmante/ prisão de ventre/ libera } \\
\text { o leite }\end{array}$ & chá & folhas \\
\hline \multicolumn{5}{|l|}{ Apocynaceae } \\
\hline $\begin{array}{l}\text { Catharanthus roseus (L.) G. Don. } \\
\text { Asteraceae }\end{array}$ & Boa Noite Branca & tosse / calmante & chá & flores \\
\hline Matricaria recutita L. & Camomila & calmante & chá & flores / folhas \\
\hline Artemisia camphorata Vill. & Cânfora & dor de cabeça / dor de estômago & chá & folhas \\
\hline Solidago chilensis Meyen & Erva lanceta & dor muscular & chá / no álcool & folhas \\
\hline \multicolumn{5}{|l|}{ Bignoniaceae } \\
\hline Arrabidea chica (HBK.) Verlot & Cajuruna & infecções na pele & chá & folhas \\
\hline Crescentia cujete L. & Coité & inflamação urinária / coluna & chá & folhas \\
\hline Tabebuia impetiginosa (Mart. Ex.DC. & Ipê Roxo & gastrite / inflamação & chá / garrafada & casca \\
\hline \multicolumn{5}{|c|}{ Standl) } \\
\hline \multicolumn{5}{|l|}{ Bixaceae } \\
\hline Bixa orellana L. & Açafrão & gastrite / machucado / eczema & chá & sementes \\
\hline \multicolumn{5}{|l|}{ Boraginaceae } \\
\hline Symphytum officinale L. & Confrei & machucado / queimadura & tópico / chá & folhas \\
\hline \multicolumn{5}{|l|}{ Caprifoliaceae } \\
\hline Sambucus nigra L. & Sabugueiro & pressão alta/ febre / dor de cabeça & chá & flores / folhas \\
\hline \multicolumn{5}{|l|}{ Celastraceae } \\
\hline Maytenus rigida Mart & Bom Nome & rins & garrafada & casca \\
\hline \multicolumn{5}{|l|}{ Costaceae } \\
\hline Costus spicatus (Jacq) Sw. & Cana de Macaco & rins & chá & folhas \\
\hline Costus spiralis (Jacq.) & Cana do Brejo & rins / pressão alta & chá & folhas \\
\hline \multicolumn{5}{|l|}{ Crassulaceae } \\
\hline Bryophyllum pinnatum (Lam.) Kurz & Corama & gastrite/ inflamação no útero & chá / garrafada & folhas \\
\hline Kalanchoe brasiliensis Cambess & Saião & gastrite / tosse / cansaço & chá & folhas \\
\hline \multicolumn{5}{|l|}{ Euphorbiaceae } \\
\hline Cnidoscolus quercifolius Pohl & Favela & coluna & chá / garrafada & casca \\
\hline Jatropha gossypiifolia L. & Pinhão Roxo & diarreia & chá & folhas \\
\hline \multicolumn{5}{|l|}{ Fabaceae } \\
\hline Cajanus cajan (L.) Millsp & Guandu & gastrite / rouquidão & chá / gargarejo & folhas \\
\hline \multicolumn{5}{|l|}{ Lamiaceae } \\
\hline Rosmarinus officinalis L. & Alecrim & $\begin{array}{l}\text { regulador de pressão arterial/ } \\
\text { colesterol / prisão de ventre / } \\
\text { calmante / reumatismo }\end{array}$ & chá & folhas \\
\hline
\end{tabular}


TABELA 1. Lista das famílias, nome científico e etnonome, indicação terapêutica, formas de uso e parte utilizada para o combate a enfermidade entre os agricultores(as) familiares no agreste paraibano nos anos de 2012-2013.

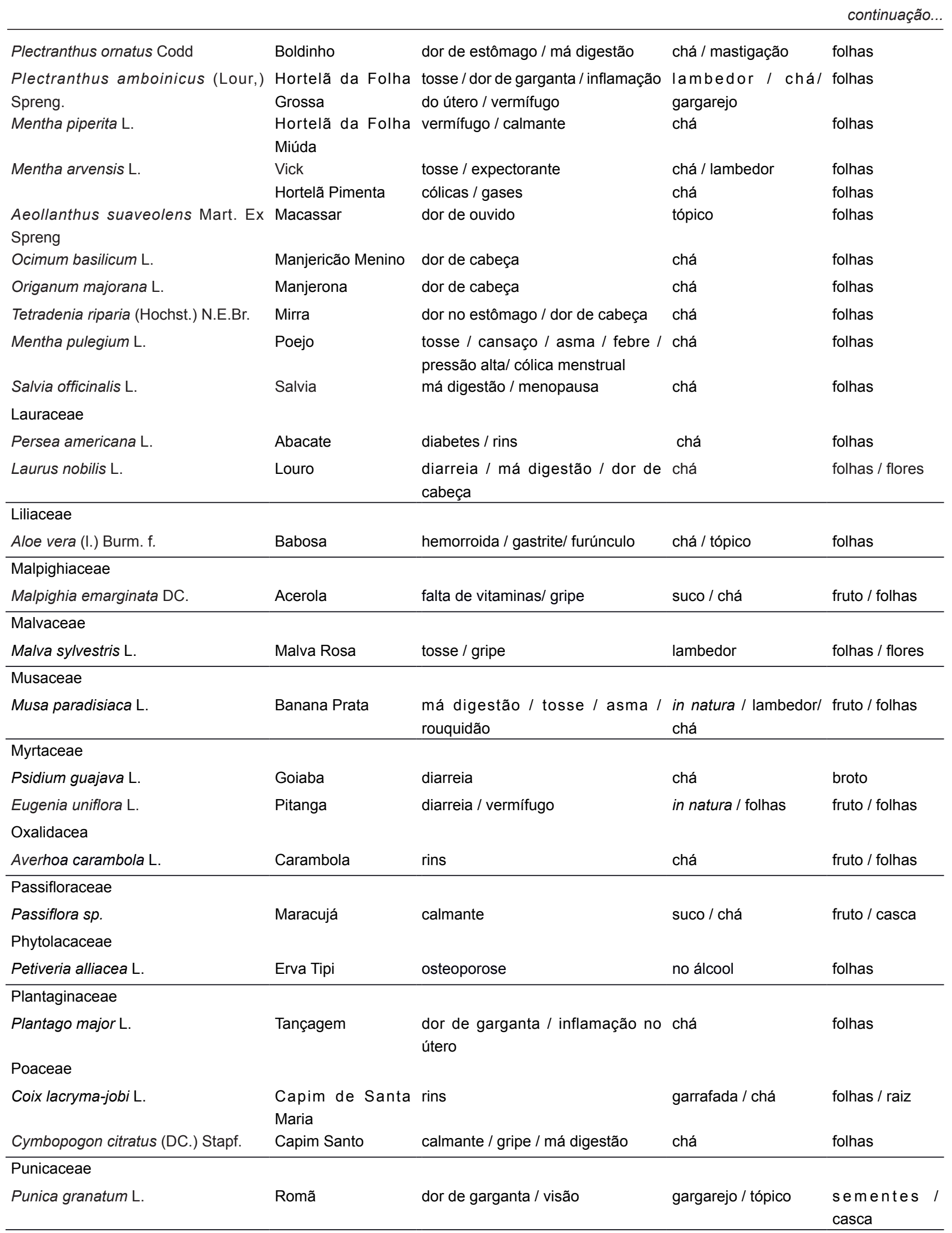


TABELA 1. Lista das famílias, nome científico e etnonome, indicação terapêutica, formas de uso e parte utilizada para o combate a enfermidade entre os agricultores(as) familiares no agreste paraibano nos anos de 2012-2013.

\begin{tabular}{|c|c|c|c|c|}
\hline Ranunculaceae & & & & \\
\hline Aconitum napellus $\mathrm{L}$. & Acônito & febre & banho / chá & folhas \\
\hline \multicolumn{5}{|l|}{ Rubiaceae } \\
\hline Morinda citrifolia L. & Noni & inibidor do câncer & suco & fruto \\
\hline \multicolumn{5}{|l|}{ Rutaceae } \\
\hline Ruta graveolens L. & Arruda & $\begin{array}{l}\text { dor de dente / dor de ouvido / cólica } \\
\text { menstrual / dor de cabeça /visão }\end{array}$ & tópico / chá / banho & folhas \\
\hline Citrus limonia L. Osbeck & Limão Cravo & limpa o sangue & suco & fruto \\
\hline \multicolumn{5}{|l|}{ Solanaceae } \\
\hline Solanum gilo Raddi & Jiló & colesterol / fígado & in natura & fruto \\
\hline Solanum paniculatum $\mathrm{L}$. & Jurubeba & má digestão/ gastrite / fígado & chá & fruto \\
\hline \multicolumn{5}{|l|}{ Verbenaceae } \\
\hline Lippia alba (Mill) N. E. Brown & Erva Cidreira & $\begin{array}{l}\text { calmante / dor de estômago / dor } \\
\text { de cabeça }\end{array}$ & chá & folhas \\
\hline \multicolumn{5}{|l|}{ Vitaceae } \\
\hline Vitis vinifera $\mathrm{L}$. & Uva & anemia & suco & fruto \\
\hline \multicolumn{5}{|l|}{ Zingiberaceae } \\
\hline $\begin{array}{l}\text { Alpinia zerumbet (Pers.) B.L. Burtt \& } \\
\text { R.M. Sm. }\end{array}$ & Colônia & febre / pressão alta / gripe & banho & folhas \\
\hline
\end{tabular}

${ }^{1}$ lambedor $=$ xarope $;{ }^{2}$ garrafada $=$ preparado de partes vegetais com álcool etílico .

e ouvido, entre outros, na forma de chá. Entretanto, seu uso indiscriminado pode acarretar em outros tipos de enfermidades, devido a sua característica tóxica. Segundo os autores Parfitt (1999) relataram que esta planta contém substâncias tóxicas, como a metilnonilcetona, que excita a motilidade do útero, sendo responsável por abortos, além de substâncias fotossensibilizantes, causadoras de lesões e queimaduras na pele e mucosas quando expostas ao sol.

Verificou-se neste trabalho que a babosa foi indicada para hemorroida, gastrite e tratamento de furúnculos. Segundo Belew (1999), o uso interno da babosa, de conhecida ação laxante devido à presença de antraquinonas, pode causar dores abdominais e irritações no intestino. Em gestantes pode provocar aborto por estimular contrações da musculatura lisa uterina. De acordo com Parfitt (1999), derivados antraquinônicos são excretados no leite materno, portanto, plantas contendo estes compostos devem ser evitados por mulheres que estão amamentando.

O uso de confrei foi também indicado para uso externo e interno no tratamento de queimaduras e machucados. De acordo com Belew (1999) e Mengue et al. (2001), esta planta contém alcalóides pirrolizidínicos, de ação carcinogênica e hepatotóxica, além de ser responsável por aborto, teratogênese e mutagênese. Por isso, o uso interno do confrei foi proibido no Brasil através da
Portaria $\mathrm{n}^{\circ} 10$ da Secretaria Nacional da Vigilância Sanitária, de 30 de janeiro de 1992. O uso desta espécie é justificado apenas em uso externo, como cicatrizante, sendo permitida a produção de medicamentos fitoterápicos de uso tópico através da Resolução RDC n 17, de 24 de fevereiro de 2000 (ANVISA, 2000).

Para a produção dos remédios caseiros, as partes das plantas mais citadas foram as folhas $(63,9 \%)$, seguida pelos frutos $(13,9 \%)$, cascas de caules $(8,3 \%)$, flores $(6,9 \%)$ e em menor proporção as sementes $(2,8 \%)$, outros $(2,8 \%$ - estratos, tinturas, açúcar) e raízes $(1,4 \%)$ (Figura 1). Por outro lado, Marinho et al. (2011), em levantamento etnobotânico de plantas medicinais realizado em área de Caatinga no município de São José de Espinharas, Paraíba, observaram que nas preparações dos remédios caseiros há predomínio da utilização das cascas do caule (38\%), seguida das folhas $(27 \%)$ e raízes (19\%). No mesmo trabalho, das 82 espécies, pertencentes a 38 famílias botânicas, $54 \%$ são espécies nativas extraídas da mata e $23 \%$ são cultivadas em quintais, o que também difere deste trabalho, no qual a maioria é cultivada nos quintais.

As partes das plantas mais comumente empregadas foram as folhas, cuja utilização se deve à facilidade de obtenção em quantidade, de manuseio e preservação das plantas, pois não impede o seu ciclo de vida, o que também foi observado por Pilla et al. (2006). 


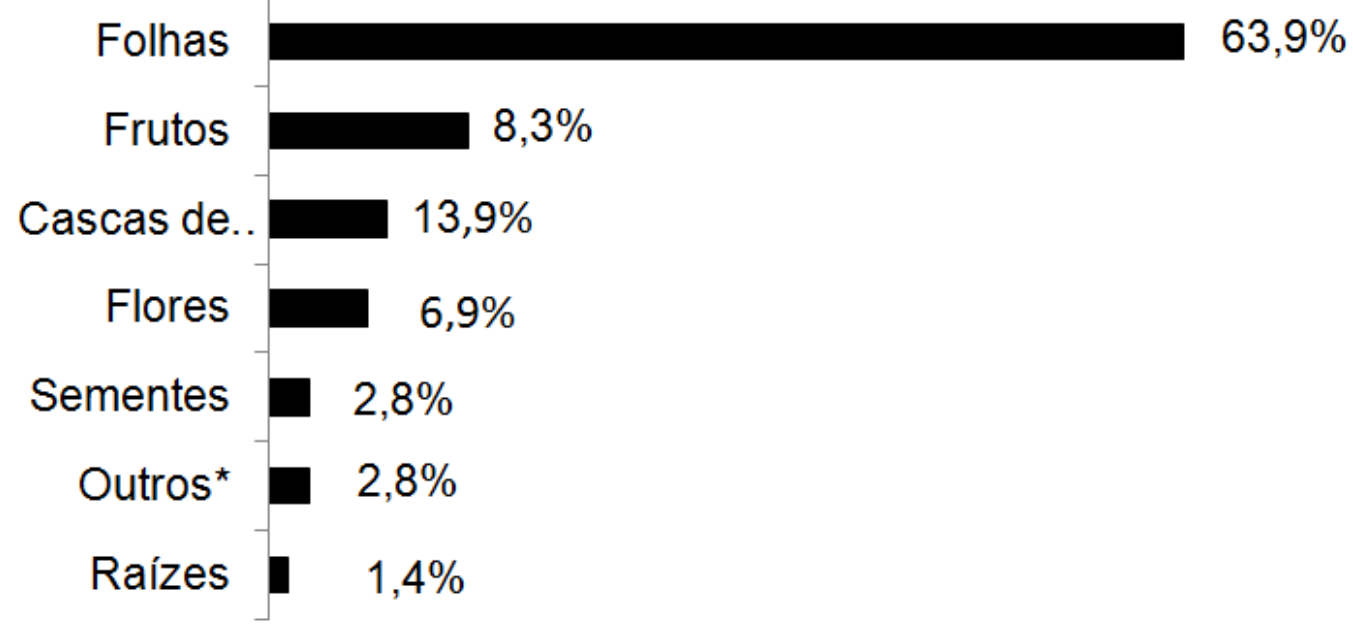

FIGURA 1. Proporçäo das partes das plantas utilizadas para a preparaçäo de remédios caseiros no agreste paraibano nos anos de 2012-2013.

*tinturas, extratos e açúcar.

Em relação às formas de uso e preparação das plantas medicinais foi verificado o predomínio do modo de administração dos remédios caseiros por via oral, que se dá pelo uso de chás, seguido pela garrafada, uso tópico, lambedor, suco, banho, gargarejo, in natura (Figura 2). O uso de chá se dá pela facilidade, praticidade e rapidez de atendimento as enfermidades tratadas pelos(as) agricultores(as) familiares.

De acordo com Agra et al. (2007), no Nordeste brasileiro alguns preparados medicinais são chamados de "garrafada", que é uma mistura de diferentes plantas, principalmente com raízes e cascas de tronco, essas maceradas e embebidas em vinho ou cachaça. Outro remédio caseiro tradicional é o "lambedor", preparado como xarope, com açúcar ou mel, utilizado principalmente como expectorante ou contra anemias.

Marinho et al. (2011), realizaram um levantamento das plantas medicinais utilizadas por uma comunidade no semiárido paraibano e verificaram que as cascas corresponderam ás partes mais utilizadas (38\%), em seguida vieram as folhas $(27 \%)$ e raízes $(19 \%)$. $E$, em relação às formas no preparo, houve o predomínio do lambedor (32\%), seguido do chá $(24 \%)$, maceração $(18 \%)$, banho $(10 \%)$ e compressas $(8 \%)$.

Doenças do sistema digestório, respiratório e genitourinário foram as indicações terapêuticas mais frequentes no uso de plantas medicinais. Para

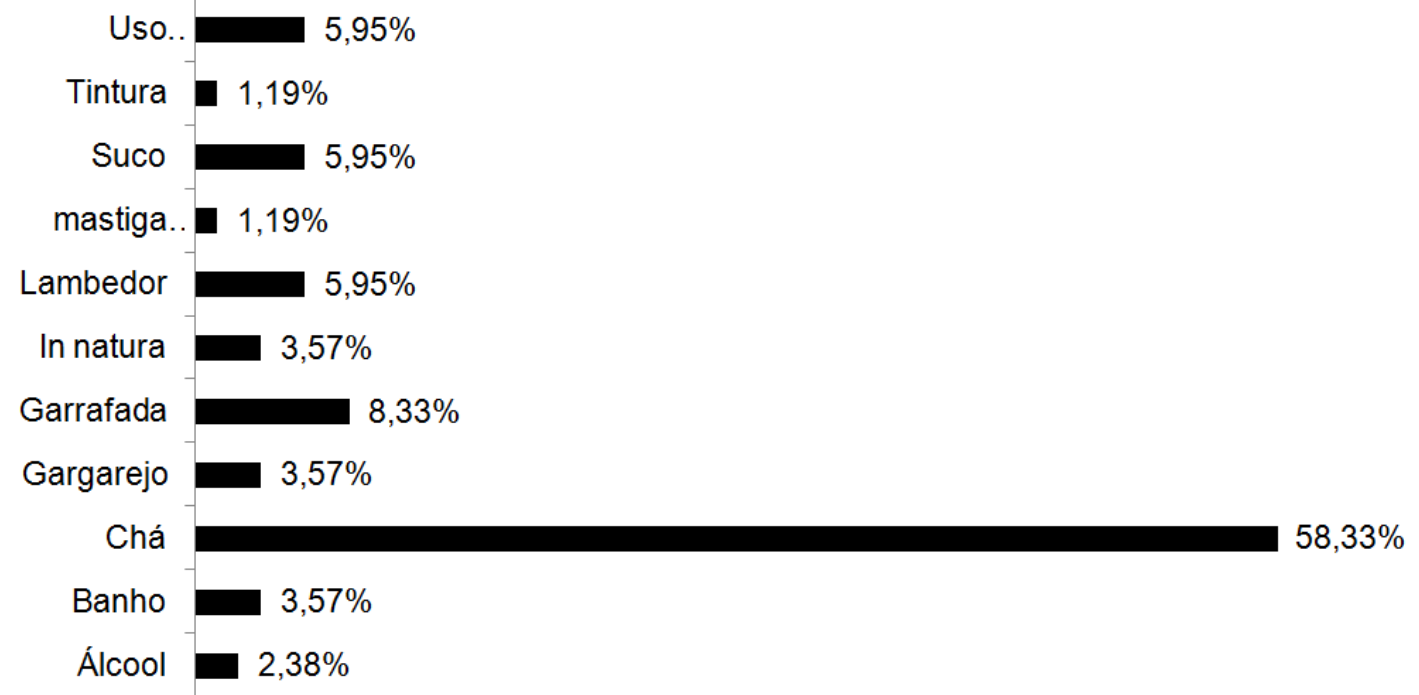

FIGURA 2. Frequência das formas de preparo das plantas medicinais usadas no agreste paraibano nos anos de 2012-2013. 
TABELA 2. Categoria de doenças, as enfermidades e a porcentagem do uso das plantas medicinais utilizadas no agreste paraibano nos anos de 2012-2013.

\begin{tabular}{|c|c|c|}
\hline Categoria* & Enfermidades & $\begin{array}{c}N^{\circ} \text { de espécies } \\
\text { citadas }\end{array}$ \\
\hline Doenças do sistema digestório & $\begin{array}{l}\text { dor de dente, prisão de ventre, dor no estômago, } \\
\text { diarreia, gastrite, gases, má digestão, fígado, } \\
\text { hemorróidas }\end{array}$ & 30 \\
\hline Doenças do sistema respiratório & $\begin{array}{l}\text { gripe, tosse, cansaço, asma, garganta, rouquidão, } \\
\text { expectorante }\end{array}$ & 23 \\
\hline $\begin{array}{l}\text { Doenças do sistema } \\
\text { genitourinário }\end{array}$ & $\begin{array}{l}\text { rins, cólicas menstruais, inflamação no ovário, } \\
\text { bexiga e útero, inflamação urinária, menopausa }\end{array}$ & 16 \\
\hline Transtornos mentais e comportamentais & calmante & 8 \\
\hline Doenças do olho e anexos & (transtorno) visão, dor de ouvido & 4 \\
\hline Doenças do sistema nervoso & dor de cabeça & 8 \\
\hline $\begin{array}{l}\text { Doenças endócrinas, nutricionais e } \\
\text { metabólicas }\end{array}$ & colesterol, diabetes, vitamina. & 6 \\
\hline Doenças do sistema circulatório & febre, pressão alta & 9 \\
\hline $\begin{array}{l}\text { Doenças do sangue e dos órgãos } \\
\text { hematopoéticos e transtornos imunitários }\end{array}$ & limpar sangue & 1 \\
\hline Doenças infecciosas e parasitárias & infecção da pele, infecção urinária, vermífugo & 5 \\
\hline $\begin{array}{l}\text { Doenças do sistema osteomuscular e do } \\
\text { tecido conjuntivo }\end{array}$ & reumatismo, dor muscular, coluna e osteoporose. & 5 \\
\hline Doenças da pele e do tecido subcutâneo & inflamação, eczema, furúnculo. & 5 \\
\hline Lesões, envenenamentos e causas externas & machucado e queimadura. & 3 \\
\hline Gravidez, parto e puerpério & aleitamento. & 1 \\
\hline Neoplasias (tumores) & câncer. & 2 \\
\hline
\end{tabular}

*Categorizadas quanto às indicações terapêuticas de acordo com a Classificação Estatística Internacional de Doenças e Problemas Relacionados à Saúde.

a categoria de doenças do sistema digestório os sintomas mais citados foram a gastrite e a diarreia. $\mathrm{Na}$ categoria doenças do sistema respiratório os sintomas mais citados foram a tosse e a gripe. $\mathrm{Na}$ categoria doenças do sistema genitourinário os sintomas mais citados foram as cólicas menstruais, a inflamação do útero, da bexiga e dos ovários (Tabela 2).

Observou-se que uma mesma planta é usada para debelar diferentes patologias, a exemplo cajueiro roxo que é utilizado para o tratamento da diabetes e das inflamações do ovário, bexiga e útero. Resultados semelhantes têm sido descritos para o bioma Mata Atlântica (Begossi et al., 2002; Pinto et al., 2006), o bioma Cerrado (Amorozo, 2004; Pilla et al., 2006), bem como confirma dados do bioma Caatinga (Almeida \& Albuquerque, 2002).

De acordo com Agra et al. (2008), realizando levantamento de plantas medicinais no Nordeste do Brasil, concluíram que os componentes químicos e as atividades biológicas da maioria das espécies encontradas não foram estudados. Os autores enfatizaram que deve haver maior investigação dessas espécies tanto em suas características farmacológicas e químicas, devido aos usos populares amplamente divulgados.

Observou-se nesta pesquisa que para o cultivo de plantas medicinais predomina a atuação de mulheres, agricultoras familiares, bem como para a responsabilidade no cuidado da saúde da família. O sistema de produção das mudas e cultivo observados são orgânicos, o que evitam os riscos da família de intoxicação por resíduos químicos, garantindo a qualidade do produto para o consumidor e principalmente a conciliação de boa produtividade com a conservação e o equilíbrio do meio ambiente.

Esse cultivo ocorre em um ambiente "faxina", terminologia tradicional relacionada à limpeza, trata-se de um viveiro constituído com madeira de agave (Agave sisalana), sentido Leste-Oeste, localizada no quintal da propriedade, oferecendo proteção contra a incidência direta do sol e de gotas de chuva, resistindo assim, às condições adversas do clima semiárido paraibano. Este sistema é de ocorrência comum na região sem

Rev. Bras. PI. Med., Campinas, v.17, n.4, supl. II, p.881-890, 2015. 
dados na literatura científica.

As mudas das plantas medicinais são produzidas em embalagens plásticas de alimentos (reutilização de sacolas contendo açúcar, arroz e feijão), com dimensões, aproximadamente, de $16,0 \mathrm{~cm}$ de diâmetro e 22,0 cm de altura. Esse material é de baixo custo, já que se aproveitam embalagens de descarte da própria residência ou embalagens doadas de vizinhos. Isto contribui também na redução de impactos ambientais no reaproveitamento dos resíduos sólidos, pois, a comunidade não dispõe de coleta pública do "lixo".

O substrato utilizado é chamado de "estrumo de basculho de agave", esse é um material rico em matéria orgânica, obtido através de sua decomposição natural e misturado com o solo. A semeadura ou a propagação das estacas e das raízes são realizadas diretamente no substrato já acondicionado nas sacolas plásticas. A utilização do resíduo de sisal como substrato orgânico se dá pelo fato da disponibilidade na região, ser de baixo custo e de fácil acesso. Segundo Silva et al. (2008), o uso empírico pelos produtores, advém da observação, quando espalham o resíduo na área de cultivo, e com o passar do tempo, as plantas que receberam este composto apresentavam-se mais desenvolvidas e com melhor vigor vegetativo.

A baixa disponibilidade de água no tempo de seca é um dos fatores restritivos da região. Por isso, as propriedades possuem sistemas de reserva e captação de água da chuva como cisternas de placas, cisternas calçadão e barreiro. Esta água é utilizada na irrigação das plantas e a irrigação é feita de forma manual com a ajuda de baldes realizada sempre em horários amenos como ao amanhecer ou à tardinha.

Observou-se também que o cultivo de plantas medicinais valoriza o resgate cultural e promove a saúde da família, pois, já não havia gastos com medicamentos. Destaca-se também, como alternativa de geração de renda, pois as mudas produzidas são comercializadas durante as visitações na propriedade, nas trocas de experiência e na feira livre da cidade de Solânea- PB. Muitas dessas plantas comercializadas são utilizadas por pessoas que participam das atividades da ONGIFA, como a divulgação das ações da experiência ou por conhecimento tradicional.

O controle de insetos indesejáveis era feito pelo uso do extrato de nem (Azadirachta indica). $\mathrm{O}$ extrato era preparado com a trituração das folhas verdes em liquidificador e posteriormente deixado em solução com água ( $50 \mathrm{~g}$ de folhas para $1,5 \mathrm{~L}$ de água), ficando em repouso por algumas horas. A pulverização nas plantas atacadas ocorria por, pelo menos, duas vezes.

\section{CONCLUSÃO}

Plantas medicinais presentes na Caatinga brasileira tem alto potencial de cultivo. Agricultores familiares do agreste paraibano possuem rico conhecimento tradicional à cerca das plantas medicinais como importante alternativa terapêutica.

Em 59 espécies identificadas de plantas medicinais ocorrentes na região do agreste, distribuídas em 36 famílias botânicas, há predomínio da família Lamiaceae.

O maior número de indicações é para tratamento de enfermidades de afecções digestivas e uma mesma planta pode ser usada para debelar diferentes patologias.

A parte mais utilizada das plantas medicinais são as folhas para o uso via oral na forma de chá.

$O$ resgate e o cultivo de plantas medicinais na região do Agreste paraibano apresentam-se como atividade de grande potencial ao desenvolvimento sustentável, sendo possível cultivar sem agrotóxicos, beneficiando diretamente na qualidade de vida e na geração de emprego e renda da família. Dessa forma, haverá a valorização do conhecimento empírico sobre plantas medicinais para que este seja mantido e perpetuado pelas gerações futuras.

\section{AGRADECIMENTO}

Os autores agradecem ao CNPq e MDA pela concessão de bolsa de estudo e dos recursos para a execução do trabalho e ao Núcleo de Ensino Pesquisa e Extensão em Agroecologia (NEPE) do CCHSA/UFPB e a ONGIFA.

\section{REFERÊNCIAS}

ALBERTASSE, P.D. et al. Plantas medicinais e seus usos na comunidade da Barra do Jucu, Vila Velha, ES. Revista Brasileira de Plantas Medicinais, v.12, n.3, p.250-260, 2010.

ALBUQUERQUE, U.P.; LUCENA, R.F.P.; ALENCAR, N.L. Métodos e técnicas para coleta de dados etnobiológicos. In: ALBUQUERQUE, U.P.; LUCENA, R.F.P.; CUNHA, L.V.F.C. (Eds.) Métodos e técnicas na pesquisa etnobiológica e etnoecológica. $1^{\mathrm{a}}$. ed. Recife: Núcleo Publicações em Ecologia e Etnobotânica Aplicada-Nupeea, 2010, p. 39-64.

ALMEIDA, C.F.C.B.R.; ALBUQUERQUE, U.P. Uso e conservação de plantas e animais medicinais no Estado de Pernambuco (Nordeste do Brasil): um estudo de caso. Interciência, v.27, n.6, p.276-285, 2002.

AGRA, M.F. et al. Survey of medicinal plants used in the region Northeast of Brazil. Brazilian Journal of Pharmacognosy, v.18, n.3, p. 472-508, 2008.

AGRA, M.F. et al. Medicinal and poisonous diversity of the flora of "Cariri Paraibano", Brazil. Journal of Ethnopharmacology, v.111, p.383-395, 2007.

AMOROZO, M.C.M. Pluralistic medical settings and

Rev. Bras. PI. Med., Campinas, v.17, n.4, supl. II, p.881-890, 2015. 
medicinal plant use in rural communities, Mato Grosso, Brazil. Journal of Ethnobiology, v.24, n.1, p. 139-161, 2004.

ANVISA. Ministério da Saúde. Agência Nacional de Vigilância Sanitária. Resolução RDC no 17 de 24 de fevereiro de 2000. Diário Oficial da União de 25 de fevereiro de 2000. Brasília. Disponível em: http://www. anvisa.gov.br/medicamentos/legis/resol.htm. Acesso em:12 fevereiro 2015.

ARNOUS, A.H. et al. Plantas medicinais de uso caseiro - conhecimento popular e interesse por cultivo comunitário medicinal. Revista Espaço para a Saúde, v.6, n.2, p.1-6, 2005.

BEGOSSI, A. et al. Medicinal plants in the Atlantic Forest (Brazil): knowledge, use and conservation. Human Ecology, v. 30, n. 3, p. 281-299, 2002.

BELEW, C. Herbs and the childbearing woman guidelines for midwives. Journal of Nurse Midwifery, v.44, n.3, p.231-252, 1999.

BRASIL. Decreto $n^{\circ}$ 5.813, de 22 de junho de 2006. Diário Oficial da União - Seção I n¹19. Poder Executivo. DF.

BRUNING, M.C.R. et al. A utilização da fitoterapia e de plantas medicinais em unidades básicas de saúde nos municípios de Cascavel e Foz do Iguaçu - Paraná: a visão dos profissionais de saúde. Ciência \& Saúde Coletiva, v.17, n.10, p. 2675-2685, 2012.

DIEGUES, A.C.; ARRUDA, R.S.V.; SILVA, V.C.F.; FIGOLS, F.A.B.; ANDRANDE, D. Saberes Tradicionais e Biodiversidade no Brasil. $1^{\text {a }}$. ed. São Paulo: NUPAUB-USP, MMA, COBIO, 2000, 211p.

FERREIRA, E.S. Agricultura Familiar no Município de Solânea (PB): o capital social no contexto do desenvolvimento territorial. 2010. 179p. Dissertação (Mestrado - Área de Concentração de Gestão Territorial) - Departamento de Geografia, Universidade de Brasília, Brasília.

GURIB-FAKIM, A. Medicinal Plants: Traditions of yesterday and drugs of tomorrow. Molecular Aspects of Medicine, v.27, n.1, p.93, 2006.

LORENZI, H.; MATOS, F.J.A. Plantas Medicinais no Brasil: nativas e exóticas. $2^{\mathrm{a}}$ ed. Nova Odessa: Plantarum, 2008, 544p.

LORENZI, H.; SOUZA, H.M. Plantas daninhas do Brasil: terrestres, aquáticas, parasitas e tóxicas. Nova Odessa: Plantarum, 2000, 349p.

MACHADO, L.H.B. As representações entremeadas no comércio de plantas medicinais em Goiânia/GO: uma reflexão geográfica. Sociedade \& Natureza, v.21, n.1, p:159-172, 2009.

MARINHO, M.G.V. et al. Levantamento etnobotânico de plantas medicinais em área de caatinga no município de São José de Espinharas, Paraíba, Brasil, Revista
Brasileira de Plantas Medicinais, v.13, n.2, p.170182, 2011.

MATOS, F.J.A.; BEZERRA, A.M.E. Plantas medicinais no Ceará-situação e perspectiva. Sob Informa, v.11, n.2, p.21-22, 1993.

MENGUE, S.S.; MENTZ, L.A.; SCHENKEL, E.P. Uso de plantas medicinais na gravidez. In: SANSEVERINO, M.T.V.; SPRITZER, D.T.; SCHÜLLER-FACCINI, L. (org.) Manual de teratogênese. $1^{\text {a }}$. ed. Porto Alegre: Editora da UFRGS, 2001, p.423-450.

MICHILES, E. Diagnóstico situacional dos serviços de fitoterapia no estado do Rio de Janeiro. Revista Brasileira de Farmacognosia, v.14, supl.1, p.1619, 2004.

MOBOT. Botanical databases/Tropicos. [online]. 2012, St. Louis: Missouri Botanical Garden, 2012. Disponível em: http://www.missouribotanicalgarden. org. Acesso em 20 de maio de 2012.

OLIVEIRA, F.C.S. et al. Plantas medicinais utilizadas em comunidades rurais de Oeiras, semiárido piauiense. Revista Brasileira de Plantas Medicinais, v.12, n.3, p.282-301, 2010.

ROQUE, A.A. et al. Uso e diversidade de plantas medicinais da Caatinga na comunidade rural de Laginhas, município de Caicó, Rio Grande do Norte (nordeste do Brasil). Revista Brasileira de Plantas Medicinais, v.12, n.1, p.31-42, 2010.

PARFITT, $\mathrm{H}$. Martindale: the complete drug reference. 32a. ed. London: Pharmaceutical Press, 1999, 4688p.

PENSO, G. The role of WHO in the selection in characterization of medicinal plants (vegetable drugs). Journal of Ethnopharmacology, v.2, n.3, p.183-188, 1980.

PILLA, M.A.C. et al. Obtenção e uso de plantas medicinais no distrito de Martim Francisco, Município de Mogi Mirim, SP, Brasil. Acta Botanica Brasilica, v.20, n.4, p.789-802, 2006.

PINTO, E.P.P. et al. Conhecimento popular sobre plantas medicinais em comunidades rurais de mata atlântica - Itacaré, BA, Brasil. Acta Botanica Brasilica, v.20, n.4, p. 751-762, 2006.

RITTER, M.R. et al. Plantas medicinais utilizadas no município de Ipê, Rio Grande do Sul. Revista Brasileira de Farmacognosia, v.12, p.51-62, 2002.

SILVA, O.R.R.F. da; et al. Cultivo do Sisal no Nordeste Brasilleiro. Circular Técnica 123. EMBRAPACNPTIA, Campina Grande, 2008, 24p.

W.H.O. ICD - 10: International statstical classification of diseases and related health problems. v.2, 10th Revision, Genebra: World Health Organization, 2010. 195p. Disponível em: <http://www.who.int/ classifications/icd/ICD10Volume2_en_2010.pdf?ua=1>. Acesso em 25 de maio de 2012. 